\title{
STUDIES ON THE FETAL HEMOGLOBIN OF RABBITS
}

\author{
Itiro Tyuma, Yasunori ENOKI AND Saburo MoRIKAWA* \\ Second Department of Physiology, Nara Medical College, \\ Kashihara, Nara, Japan
}

\begin{abstract}
Since KORBER ${ }^{1)}$ discovered in 1865 that human fetal hemoglobin is more resistant to alkali than the adult one, numerous works indicating differences in properties of the fetal and the adult pigment have been published. Biochemically, a considerable dissimilarity is found in their amino acid compositions and primary structures, i. e. amino acid sequences ${ }^{23}$. Physiologically, it has long been known that human fetal blood shows a higher oxygen affinity than maternal blood ${ }^{3,4,5,6)}$. The difference can also be observed in red cell suspensions ${ }^{7}$. The characteristic feature of fetal blood has been ascribed to that of fetal hemoglobins contained in the fetal blood ${ }^{8,9}$. On the other hand, AlLEN et al. ${ }^{10)}$ suggested that some environmental factors, rather than the hemoglobin molecules themselves, play a determinate role in the human fetalmaternal difference in their oxygen equilibrium.

It is a purpose of this paper to elucidate this problem and to confirm fetal-maternal differences in rabbit hemoglobin from various aspects. The study may throw some light on the physiological significance of the fetal hemoglobin.
\end{abstract}

\section{MATERIALS AND METHODS}

Whole blood. The pooled blood from several littermates of rabbits of various gestational ages taken by cesarean section and the blood of newborn rabbits of various ages were used. Blood of maternal rabbits and human adults were also employed as a reference material. Potassium ammonium oxalate was used as an anticoagulant.

Preparation of hemoglobin solution. Packed red cells obtained by repeated washings of the oxalated blood with physiological saline were divided into two parts. The one received the equal volume of deionized water and 0.25 volume of toluol. In the other the deionized water was replaced by carbon monoxide saturated water. After vigorous shaking for 10 minutes, the mixtures were left stand for 24 hours at $2^{\circ} \mathrm{C}$ for complete hemolysis. Then the hemolysates were submitted to centrifugation at $4000 \mathrm{r}$. p. m. for 20 minutes to remove toluol and stroma, yielding oxy- and carboxy-hemoglobin solutions, respectively. Occasionally, the hemoglobin solutions thus obtained were further

Received for publication July 14, 1964.

*中馬一郎, 榎 泰義, 森川三郎 
purified by dialysis against frequent changes of deionized water or other appropriate solutions.

Alkali denaturation. Denaturation of oxy-hemoglobin in $0.1 \mathrm{~N}$ sodium hydroxide was followed by JoNXIS \& VISSER's method ${ }^{11}$, by measuring optical density decrease at $576 \mathrm{~m} \mu$. The kinetics of denaturation was analyzed by plotting logarithm of percentage of undenatured hemoglobin against time.

Ultraviolet spectrophotometry. Optical density of oxy-and carboxy-hemoglobin solutions was determined in a wave length region between 240 to $310 \mathrm{~m} \mu$. The concentration of hemoglobin in each sample was adjusted to give the same optical density at $275 \mathrm{~m} \mu$ for the sake of comparison.

Starch-gel electrophoresis. Smithies' horizontal starch-gel electrophoretic technique ${ }^{12}$ ) was used. The electrophoretic run was carried out in Poulik's discontinuous buffer system $^{13)}$ under voltage gradient of $10 \mathrm{~V} / \mathrm{cm}$ and at 0 to $2^{\circ} \mathrm{C}$ for 3 to 4 hours. Carboxyhemoglobin solution blotted in a small piece of filter paper was inserted into a slit prepared in the gel.

After the run, the gel was bisected, and the one was stained with amido black $10 \mathrm{~B}^{12)}$ or bromophenol blue ${ }^{14)}$ and the other with benzidine ${ }^{15)}$ or $o$-dianisidine ${ }^{16}$. Densitometric scanning was performed on the glycerol-cleared ${ }^{14}$ half gel slices by a Toyo type I manual densitometer.

Determination of reactive $S H$ groups. Reactive $\mathrm{SH}$ groups in the globin moiety of hemoglobin was determined by BOYER's $p$-chloromercuribenzoate method ${ }^{17)}$. The results were analyzed by plotting the optical density increment at $250 \mathrm{~m} \mu$ against hemoglobin concentration which was determined by cyanmet-hemoglobin method taking molecular weight of the protein as 68,000 . Concentration of the reagent was calculated from optical density at $232 \mathrm{~m} \mu$, taking molar absorbancy index as $1.69 \times 10^{4}$.

\section{Construction of oxygen equilibrium curve.}

Whole blood. ENokI's method ${ }^{18)}$ was slightly modified. A half $\mathrm{ml}$ of fresh blood was equilibrated with 6 different partial pressures of oxygen $\left(p \mathrm{O}_{2}\right)$ under a constant carbon dioxide partial pressure $\left(p \mathrm{CO}_{2}\right)$ in a tonometer of approximately $90 \mathrm{ml}$ capacity at $37.5^{\circ} \mathrm{C}$. After the gas and temperature equilibrium had been attained, gas analysis was performed on the gas phase and blood by a HALDANE's gas analyzer and a micromanometric apparatus recently developed by VAN SLYKe \& PLAZIN ${ }^{19)}$, respectively.

Hemoglobin solution. A spectrophotometric procedure with a cell-fused tonometer (optical path length $2.5 \mathrm{~mm}$ ) as previously described by one of the present authors ${ }^{20)}$ was used. Hemoglobin solution was first deoxygenated in the tonometer by repeated evacuation nitrogen flushings and temperature equilibration. After complete deoxygenation, a measured amount of air was successively injected into the tonometer, followed by temperature equilibration. Equilibrium oxygen pressure was calculated from the amount of air injected, room temperature, equilibrium temperature, barometric pressure, volume of gas phase in the tonometer, and a correction for the oxygen combined with hemoglobin. Percentage oxygen saturation, $y$, was computed from changes in the optical density at $650 \mathrm{~m} \mu$.

In these studies, analysis of equilibrium data was made by applying Hill's empirical equation:

$$
\frac{y}{100}=\frac{\mathrm{K} p^{n}}{1+\mathrm{K} p^{n}}
$$


where $p$ denotes equilibrium oxygen pressure and $n$ and $\mathrm{K}$ are constants. The magnitude of heme-heme interaction was tentatively expressed by the value of " $n$ " as calculated from the oxygen equilibrium data and the oxygen affinity was indicated by $p_{50}$, i. e. the oxygen pressure at which $50 \%$ oxygenation of hemoglobin was displayed.

All optical density measurements were performed by a Shimadzu QR-50 photoelectric spectrophotometer except that a Shimadzu SV-50 self-recording photoelectric spectrophotometer was used in some ultraviolet absorption studies.

\section{RESULTS}

Whole blood oxygen equilibrium curve. FIG. 1 shows oxygen equilibrium curves of whole blood of adult, neonatal, and infant rabbits of various postnatal days

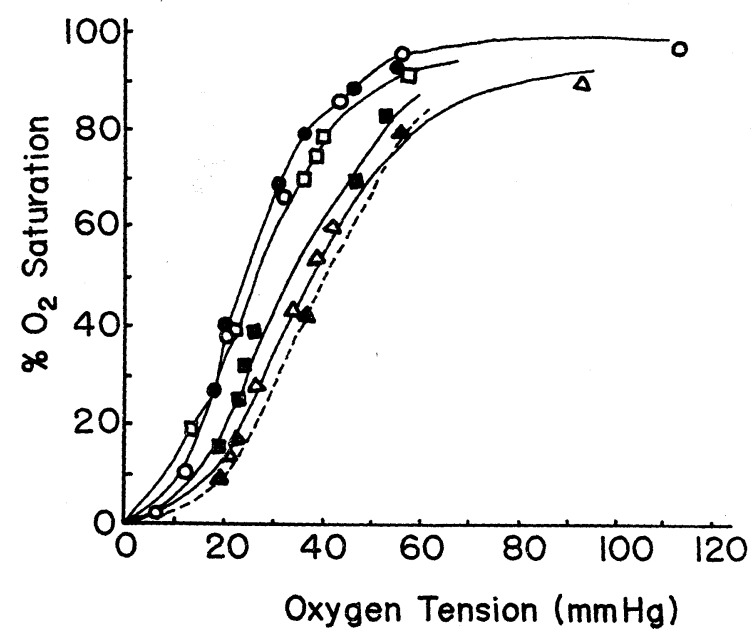

Fig. 1. Whole blood oxygen equilibrium curves in neonatal, infant, and adult rabbits under the carbon dioxide pressure of $40 \mathrm{mmHg}$ and the equilibrium temperature of $37 .{ }^{\circ} \mathrm{C}$.

$\bigcirc-\bigcirc$; postnatal, 1 day.

$\square-\square$; postnatal, 17 day.

$\triangle-\triangle$; postnatal, 34 day.

; postnatal, 7 days.

-1- postnatal, 24 days.

$\boldsymbol{\Lambda}-\boldsymbol{\Lambda}$; maternal.

TABLE 1

Postnatal changes in the oxygen equilibrium characteristics of rabbit blood.

Equilibrium $\mathrm{CO}_{2}: 40 \mathrm{mmHg}$. Equilibrium temperature : $37.5^{\circ} \mathrm{C}$.

\begin{tabular}{c|c|c}
\hline Postnatal days & " $n$ " in HiLL's equation & $p_{50}$ \\
\hline 1 & 2.9 & 24 \\
7 & 2.8 \\
17 & 3.0 & 24 \\
24 & 2.8 & 27 \\
34 & 2.8 & 33 \\
Maternal & 2.9 & 36 \\
\hline
\end{tabular}


under the carbon dioxide pressure of $40 \mathrm{mmHg}$ and the equilibrium temperature of $37.5^{\circ} \mathrm{C}$. The index of oxygen affinity $\left(p_{50}\right)$ and magnitude of hemeheme interaction $(n)$ obtained from the curves are summarized in TABLE 1.

Evidently, blood of neonatal rabbits shows a higher oxygen affinity than the maternal one and the difference gradually disappears along with the postnatal development. On the other hand, all the curves present similar S-shaped forms with nearly identical $n$-values (2.8 to 3.0 ), indicating that the magnitude of heme-heme interaction is consistently the same in all the bloods.

Oxygen equilibrium curve of hemoglobin solution. In order to clarify the nature of the above differences in the adult and infant bloods, the oxygen equilibrium studies have been carried out on hemoglobin solutions prepared from the two types of blood.

The results obtained in $0.1 \mathrm{M}$ phosphate buffer of $\mathrm{pH} 6.8$ and 7.4 at $20^{\circ} \mathrm{C}$ are represented in Fig. 2. As clearly seen in the figure, the curve for fetal (25 gestational days) hemoglobin lies to the left of that for maternal one at both the pH's, whereas all the curves display a similar typical S-shape. The characteristics of these curves quantitatively estimated are shown in TABLE 2. Thus, the results with hemoglobin solutions substantially accord with those obtained with the whole bloods, suggesting the existence of functionally disparate hemoglobins in adult and fetal rabbit bloods. However, in view of

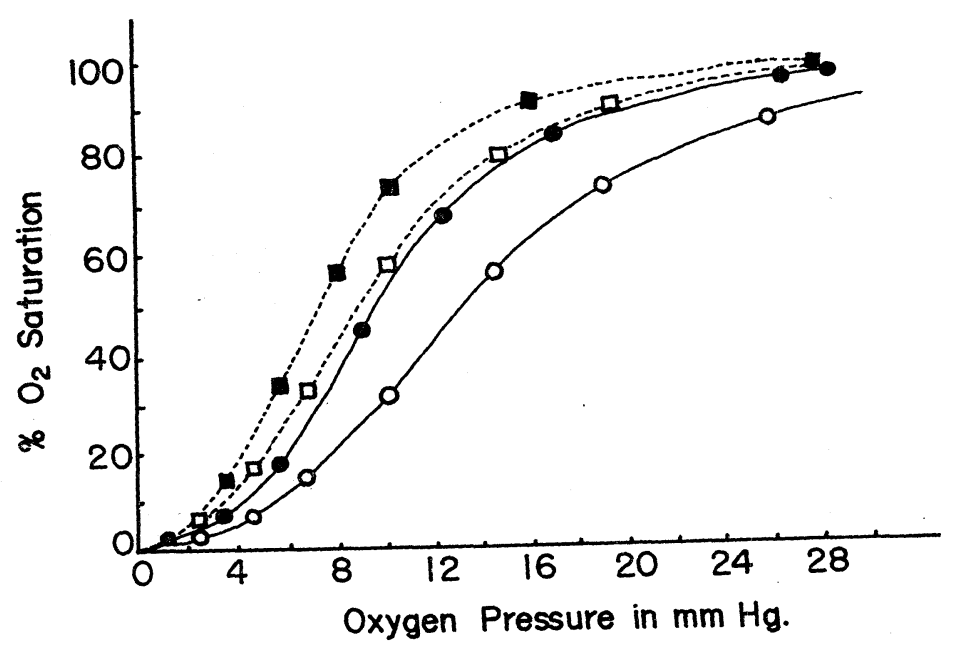

FIG. 2. Oxygen equilibrium curves of adult and fetal rabbit hemoglobins at two different pHs.

Equilibrium temperature; $20^{\circ} \mathrm{C}$. Medium; $0.1 \mathrm{M}$ phosphate buffer.

- fetal, at $\mathrm{pH} 7.4$.

$\square-\square$; fetal, at pH 6.8 .

- maternal, at $\mathrm{pH} 7.4$.

$\bigcirc-\bigcirc$; maternal, at $\mathrm{pH} 6.8$.

"fetal" refers to a pooled hemoglobin sample from 4 littermates of 25 gestational days. 
TABLE 2

Oxygen equilibrium characteristics of adult and fetal rabbit hemoglobins at two different $\mathrm{pH}$ 's.

Medium : $0.1 \mathrm{M}$ phosphate buffer. Temperature : $20.0^{\circ} \mathrm{C}$.

\begin{tabular}{l|c|c|c}
\hline Hemoglobin & $\mathrm{pH}$ & $p_{50}(\mathrm{mmHg})$ & $n$ \\
\hline Fetal* & 7.4 & 7.5 & 2.8 \\
& 6.8 & 9.1 & 2.8 \\
Maternal & 7.4 & 9.9 & 2.8 \\
& 6.8 & 13.4 & 2.8 \\
\hline
\end{tabular}

* Pooled from 4 littermates of 25 gestational days.

ALLEN et al's observation ${ }^{10)}$ on human adult and fetal hemoglobins, further approach has been attempted to this problem.

FIG. 3 and TABLE 3 show the effect of dialysis upon the oxygen equilibrium characteristics of adult and fetal rabbit hemoglobins. The hemoglobin solutions obtained from adult and fetal red cells by hemolysis and destromatization have been dialyzed against a large amount of deionized water in one and common vessel for 20 hours at $0^{\circ} \mathrm{C}$. The above established difference in the oxygen affinity and equality of $n$-value between the adult and fetal pigments still remained almost unchanged even after the dialysis.

These results crucially indicate that the fetal-maternal difference in the oxygen affinity, at least in this species, is attributable to the difference in the hemoglobin molecule, reasonably globin moiety, itself. Therefore, it has been

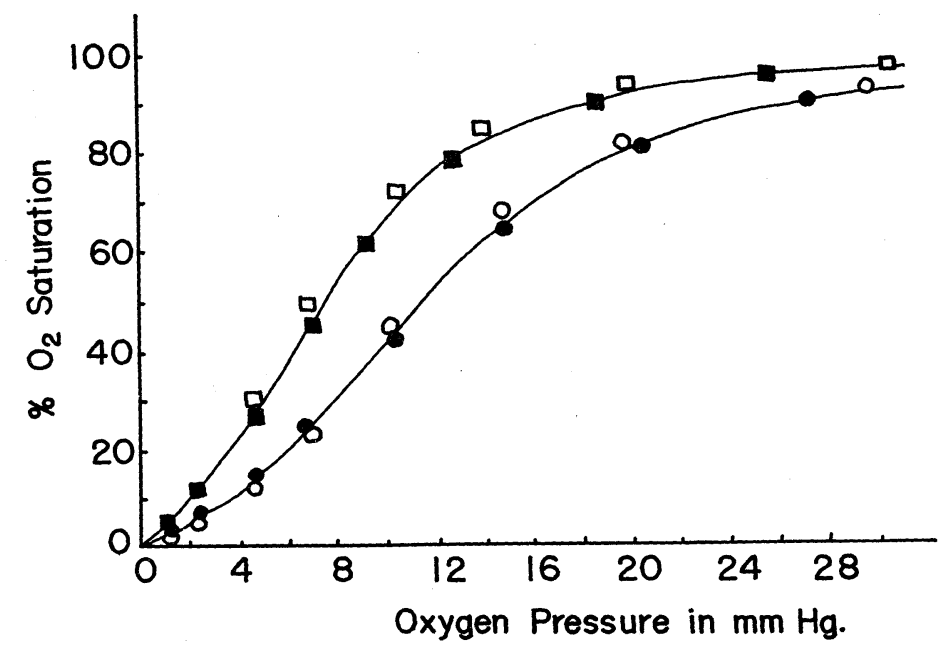

Frg. 3. Effect of dialysis upon the oxygen equilibrium of adult and fetal rabbit hemoglobins.

Equilibrium temperature; $20^{\circ} \mathrm{C}$. Medium; $0.1 \mathrm{M}$ phosphate buffer ( $\mathrm{pH} 7.4$ ).

- ; fetal, undialyzed.

$\square-\square$; fetal, dialyzed
- maternal, undialyzed. $\bigcirc-\bigcirc$; maternal, dialyzed. 
TABLE 3

Effect of dialysis of adult and fetal hemoglobins upon their oxygen equilibrium characteristics.

Oxygen equilibrium conditions: $0.1 \mathrm{M}$ phosphate buffer $(\mathrm{pH} 7.4)$ and $20.0^{\circ} \mathrm{C}$.

\begin{tabular}{c|c|c|c|c}
\hline \multirow{2}{*}{ Hemoglobin } & \multicolumn{2}{|c|}{$p_{50}(\mathrm{mmHg})$} & \multicolumn{2}{|c}{$n$} \\
\cline { 2 - 4 } & $\begin{array}{c}\text { Before } \\
\text { dialysis }\end{array}$ & $\begin{array}{c}\text { After } \\
\text { dialysis }\end{array}$ & $\begin{array}{c}\text { Before } \\
\text { dialysis }\end{array}$ & $\begin{array}{c}\text { After } \\
\text { dialysis }\end{array}$ \\
\hline Fetal* & 7.5 & 7.0 & 2.8 & 2.8 \\
Adult & 11.6 & 11.2 & 2.8 & 2.9 \\
\hline
\end{tabular}

* Pooled from 4 littermates of 25 gestational days.

attempted to disclose differences of chemical and physico-chemical properties. of both the proteins.

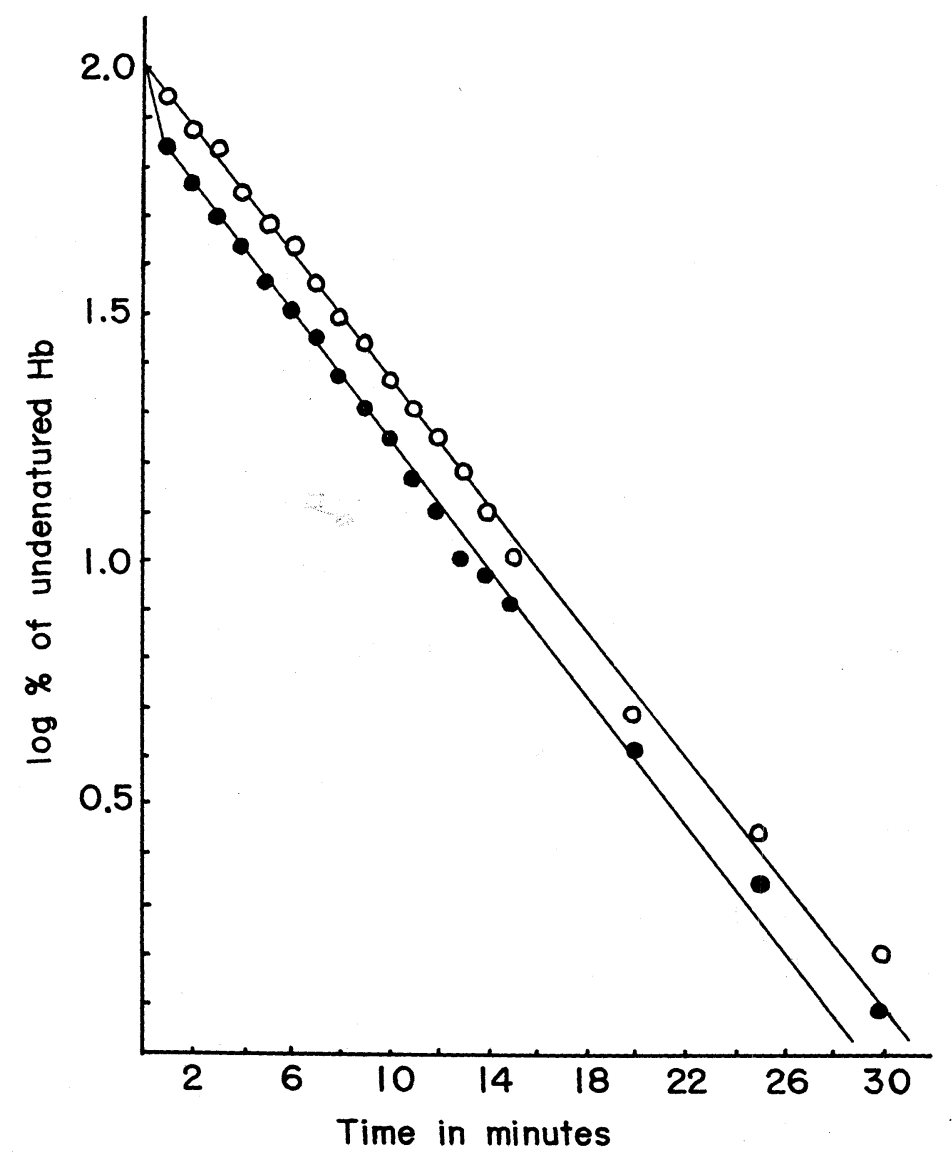

FIG. 4. Alkali denaturation curve of fetal and adult rabbit oxy-hemoglobins.

O-O; maternal.

Medium; $0.1 \mathrm{~N} \mathrm{NaOH}$.

- - fetal (25 gestational days).

Temperature; $20^{\circ} \mathrm{C}$. 
Alkali denaturation behavior. FIG. 4 depicts the alkali denaturation curves of maternal and fetal (25 gestational days) hemoglobins obtained in $0.1 \mathrm{~N}$ sodium hydroxide at $20^{\circ} \mathrm{C}$. The maternal hemoglobin apparently conforms the onecomponent first order reaction kinetics, whereas the fetal one shows 10 to $20 \%$ of a distinct rapidly denaturing component besides the main component which is identical in the denaturation behavior with the maternal one. Followup studies on newborn rabbits reveal that the minor component gradually diminishes as the postnatal growth proceeds. The alkali denaturation behavior of hemoglobin of 35 days-old rabbits was indistinguishable from that of the adult.

Ultraviolet absorption spectrum. Ultraviolet absorption spectrum of oxyhemoglobin of adult and newborn rabbits of various ages was determined in

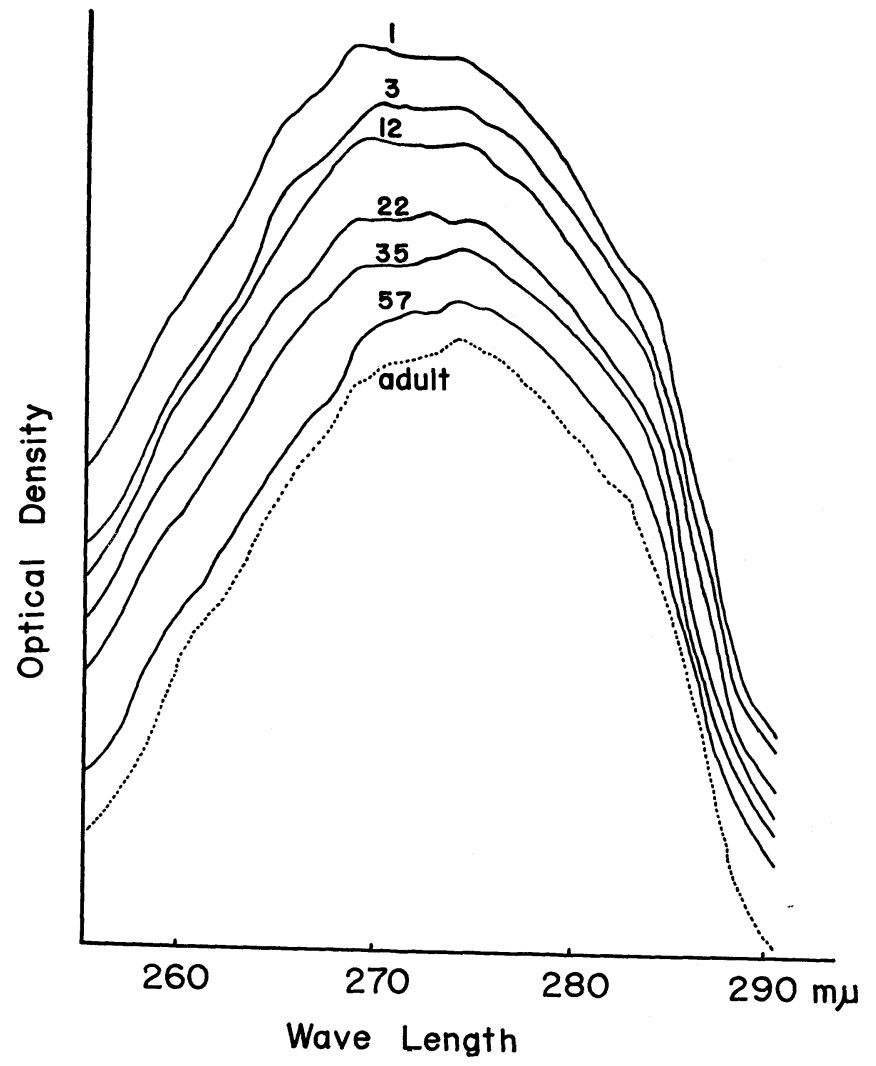

FIG. 5. Postnatal change in the ultraviolet absorption spectrum of rabbit oxy-hemoglobin.

Broken line represents the spectrum of adult rabbit hemoglobin and the figures attached to each curve refer to the postnatal days.

Each curve corresponds to approximately equal concentration of the hemoglobin, but for clarity have been displaced along the ordinate which is linear in optical density. 
$0.025 \mathrm{M}$ phosphate buffer ( $\mathrm{pH} 7.52$ ) at room temperatures. As illustrated in FIG. 5, a minor but distinct difference is observed in the spectrum between adult and fetal (one postnatal day) oxy-hemoglobins. The absorption maximum in the fetal pigment is displaced by about $5 \mathrm{~m} \mu$ to shorter wave length side than in the adult one; the maximum at $269 \mathrm{~m} \mu$ found in the fetal hemoglobin gradually decreases as the postnatal days proceed, and it is displaced at $274 \mathrm{~m} \mu$ in the adult hemoglobin. The spectrum of the hemoglobin of 57 days-old rabbits is almost the same with that of the adult. A shoulder due to tryptophan is observed around $290 \mathrm{~m} \mu$ in all the pigments, although no significant difference is found among them in the shape and position of the shoulder in contrast with the marked disparity noticed in the fine structure between human adult and fetal hemoglobins ${ }^{211}$.

A similar but less postnatal change of the absorption spectrum is observed in carboxy-hemoglobin, in which a shoulder around $273 \mathrm{~m} \mu$ continually increases with the lapse of postnatal days.

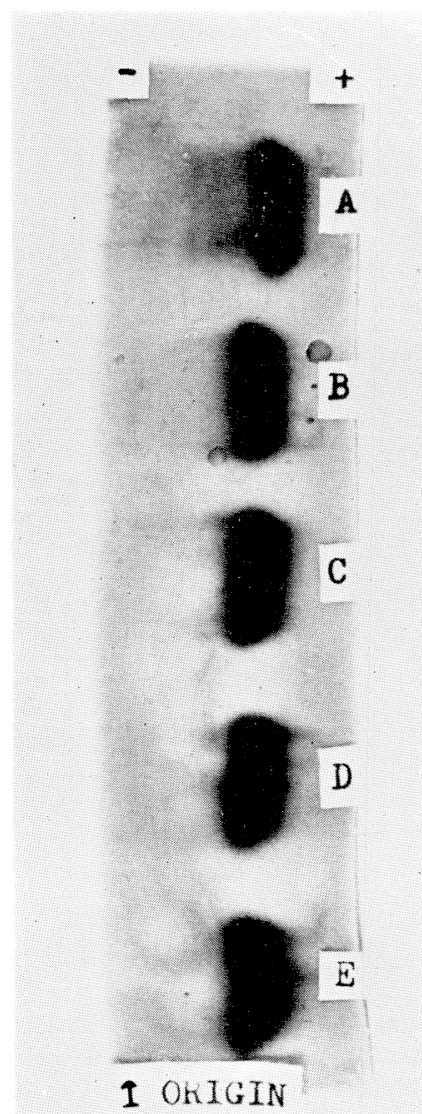

FIG. 6. Starch-gel electrophoretic pattern of rabbit fetal and maternal and human adult carboxy-hemoglobins at $\mathrm{pH}$ 8.6 .
A : human adult.
B: rabbit maternal.
C: rabbit fetal (2 postnatal days).
D: rabbit fetal (17 postnatal days).
E: rabbit fetal (24 postnatal days).
Amido black $10 \mathrm{~B}$ staining. 
Starch-gel electrophoresis. Starch-gel electrophoresis is performed on carboxyhemoglobin of maternal, newborn, and fetal rabbits of various ages and human adults. A typical electrophoretic pattern is presented in FIG. 6. Evidently there exists no significant difference between the maternal and newborn rabbits, irrespectively of their ages. The identity of electrophoretic mobility is also confirmed with the maternal and fetal hemoglobins of rabbits of various gestational ages. FIG. 6 further demonstrates that under the experimental condition employed the rabbit hemoglobins show a little lower mobility than the main component of human adult hemoglobin.

Densitometric scanning of glycerol-cleared gel strips shows apparent homogeneous nature of both the maternal and fetal hemoglobin. Flat cuvette chromatography ${ }^{22)}$ with cation exchanger resin, Amberlite XE 64, also yields the similar results. The observed electrophoretic homogeneity of adult rabbit hemoglobin agrees with the results obtained by several workers ${ }^{23,24,25)}$ using paper or agar-gel electrophoretic technique.

Reactive SH groups. A typical result of adult and fetal (25 gestational days) rabbit hemoglobins is shown in FIG. 7. Calculation of reactive $\mathrm{SH}$ groups from the titration curves revealed the figure of 2.2 and 3.0 moles SH per one mole of hemoglobin for the fetal and adult pigments, respectively.

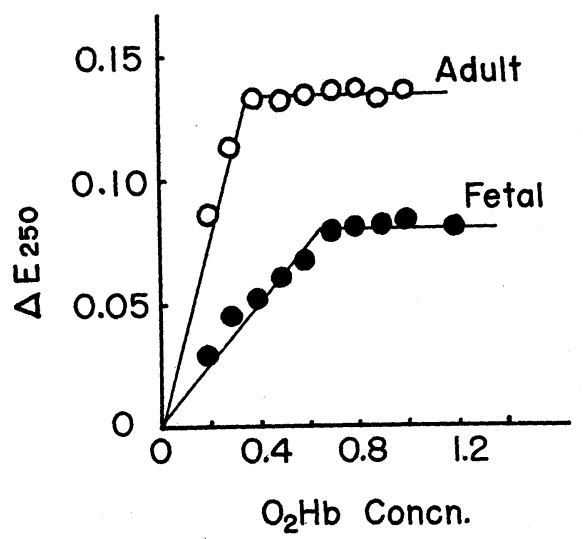

FIG. 7. $p$-Chloromercuribenzoate titration of dialyzed adult and fetal rabbit oxy-hemoglobins.

$\bigcirc-\bigcirc$; maternal.

- f fetal (25 gestational days).

Ordinate; optical density increment at $250 \mathrm{~m} \mu$.

Abscissa; concentration increment of hemoglobin in an arbitrary unit.

TABLE 4 includes the results of a follow-up study on newborn rabbits of a same litter. Clearly, the reactive SH content increases steadily with the increase of postnatal days and the figure for 57 days-old rabbits practically 
TABLE 4

Change"in $p$-chloromercuribenzoate (PCMB) titer of dialyzed rabbit oxy-hemoglobin with the age after gestation and parturition.

\begin{tabular}{l|c}
\multicolumn{1}{c|}{ Age } & PCMB titer/mole $\mathrm{O}_{2}-\mathrm{Hb}$ \\
\hline Fetal : 25 gestational days & 2.2 \\
Postnatal : 14 days & 2.3 \\
Postnatal : 35 days & 2.7 \\
Postnatal : 57 days & 3.1 \\
Maternal & $3.0 \quad 3.3$ \\
\hline
\end{tabular}

coincides with that for the adult. The change paralleles with that of the ultraviolet absorption spectrum described above.

\section{DISCUSSION}

HASSELHORST \& STROMBERGER ${ }^{3)}$ first demonstrated that the oxygen equilibrium curve of human fetal blood shifts to the left side of that of the adult one. Further studies on this problem have been carried out by several investigator ${ }^{4,5,6)}$, confirming the higher oxygen affinity of the fetal blood. In view of the works of BARCROFT and his school ${ }^{8)}$ and LEIBSON et al. ${ }^{9)}$, the difference in the physiological function of both the bloods has long been attributed to the distinct hemoglobins contained in them.

On the other hand, HAUROWITZ ${ }^{26)}$ and MCCARTHY ${ }^{7)}$ later found that the oxygen affinity of the hemoglobin solution prepared from human fetal blood is less than that of the adult hemoglobin solution. Furthermore, AlLEN et al. ${ }^{10)}$ observed that the oxygen affinity of the fetal hemoglobin is essentially the same with that of maternal one after the simultaneous dialysis against a common medium. Moreover, a recent study ${ }^{27}$ ) performed on blood from an adult patient with "the high fetal gene" disclosed the normal oxygen equilibrium characteristics of the blood inspite of its high $(69 \%)$ fetal hemoglobin content. Thus, the above view has been thought to be inadequate at least for human fetal and maternal bloods ${ }^{28)}$.

The results of the present study clearly indicate a higher oxygen affinity of neonatal blood than maternal one in rabbits (FIG. 1 and TABLE 1). This accords with the results of BARRON \& MESCHIA ${ }^{29)}$ on the same species and those of various investigators on several animal species including human subjects. However, the continuous decrease of the oxygen affinity to the adult level with the postnatal development contrasts with the postnatal changes noticed in man, sheep, and goat, in which a decrease below the adult level is always discernible in an early period of postnatal lif $\mathrm{e}^{30,31,32}$.

On the contrary to human hemoglobins, rabbit fetal hemoglobin exhibited a higher oxygen affinity than maternal one at the two pH's in the state of 
solution (FIG. 2 and TABLE 2). Furthermore, the difference still remained with. little change even after the complete dialysis against deionized water. The $p_{50}$ values obtained at $\mathrm{pH} 7.4$ for both the pigments substantially agree with those reported by $\mathrm{HALL}^{33)}$, who gave 7 to 9 and 11 to $12 \mathrm{mmHg}$ for the fetal (23 gestational days) and adult hemoglobin, respectively, at the same $\mathrm{pH}$. Comparison of the $p_{50}$ value at the two pH's (TABLE 2) suggests that the fetal pigment presents less Bohr effect than the maternal one, although more careful studies covering wider $\mathrm{pH}$ range are required to draw a more exact conclusion on this problem. No significant difference was observed in the magnitude of heme-heme interaction ( $n$-values) between adult and fetal hemoglobin irrespectively of their environments.

Dissimilarity of the hemoglobins was substantiated in some physicochemical properties as well. The distinction in their ultraviolet absorption. spectra (FIG. 5) may reflect a difference in the molecular structure of the proteins, i. e. difference in the content of aromatic amino acids or the physicochemical property of the protein molecule in which the amino acids are incorporated, or both. The view is also supported by their distinction in alkali denaturation behavior and reactive SH content (FIG. 4 and TABLE 4). Thus, it can be safely argued that fetal and adult rabbit hemoglobins differ in molecular structure as well as in physiological function and the former is. gradually replaced by the latter during the early period of life.

The difference in the molecular structure, however, may be a subtle one. as MULLER ${ }^{34}$ ) suggested, since both kinds of hemoglobin showed the same. mobility on starch-gel electrophoresis (FIG. 6) and the major component of the fetal pigment displayed an alkali denaturation behavior essentially similar to that of the adult one. These properties are said to be dependent on the gross structure of the molecule.

According to modern knowledges of the structure of hemoglobin, the pigment contains many aromatic amino acid residues, some of which lie in the vicinity of heme groups. Thus, any changes of the amino acid residue may affect the oxygen affinity of the heme group and Bohr effect which is ascribed to the ionization of heme-linked acid groups. It becomes highly probable, therefore, that the structural differences are responsible for the distinction in the physiological function. Hence, the physiological significance of the fetal hemoglobin may be explained, at least in this species, in terms of the adaptation at molecular level to the intrauterine environment of low ambient oxygen tension.

The figures obtained for the reactive SH content of the adult hemoglobin (TABLE 4) is evidently higher than those reported by RIGGS ${ }^{35)}$ and CECIL \& SNOW ${ }^{36}$ ), 1.9 and 2.3 moles per one mole of the protein, respectively. The different reactivity of heavy metal reagents used by these workers may be responsible for the difference. In this connection, it is worthwhile to mention 
the study of RIGGS ${ }^{35)}$, who found a linear relation between the number of reactive SH groups and the magnitude of Bohr effect in hemoglobins of various animals. In his results, however, the figure for adult rabbit deviate considerably from the straight line. If we adopt our present data for the reactive $\mathrm{SH}$ content and RiGGs' result for the magnitude of Bohr effect $\left(\Delta \log p_{50} / \Delta \mathrm{pH}\right.$ $=-0.75)$, the deviation becomes hardly noticeable as illustrated in FIG. 8.

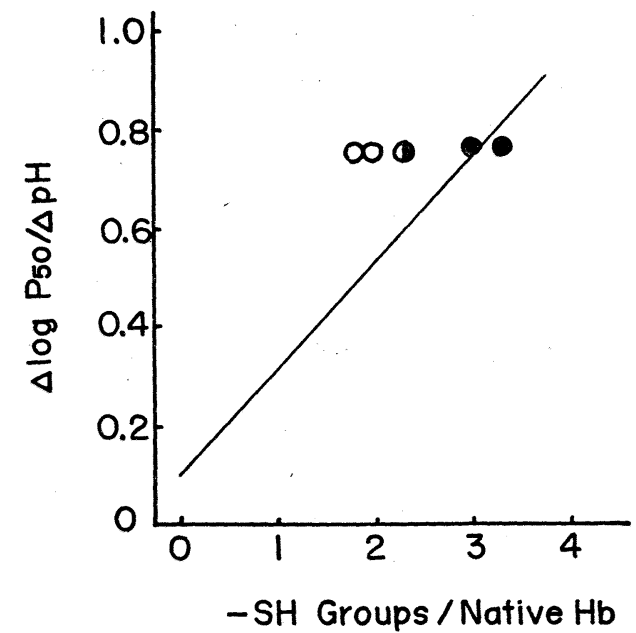

FIG. 8. Relation between the magnitude of Bohr effect and sulfhydryl reactivity of native rabbit' oxy-hemoglobin.

The straight line is drawn according to RIGGS' data on various mammals ${ }^{35)}$.

$O$; RIGGS' data on adult rabbit ${ }^{35}$.

D; CeCIL \& SNow's data on adult rabbit ${ }^{36)}$.

- Present results on adult rabbit.

Calculation from RigGs' straight line enables us to presume that $\Delta \log p_{50} / \Delta \mathrm{pH}$ for fetal rabbit hemoglobin may be around -0.58 .

\section{SUMMARY}

1. Neonatal rabbit blood exhibits a higher oxygen affinity than the maternal one and the difference gradually disappears as the postnatal age develops. The circumstance is also ascertained in the hemoglobin solution prepared from the fetal and maternal blood and the difference shows little alteration after the 20 hours' dialysis against deionized water in one and common vessel. No significant difference can be verified in the magnitude of heme-heme interaction between both kinds of hemoglobin irrespectively of their environments. 2. Minor but distinct differences are found between the fetal and adult oxyhemoglobins in the alkali denaturation behavior and the ultraviolet absorption 
spectrum and the dissimilarities disappear as the postnatal growth proceeds. 3. Starch-gel electrophoresis of both the adult and fetal carboxy-hemoglobins showed single homogeneous zone of the same mobility.

4. $p$-Chloromercuribenzoate titer per mole of the fetal oxy-hemoglobin is estimated as 2.2 and it increases gradually along with the postnatal development, reaching the figure of 3 or so in the adult ones.

5. These results are discussed in the light of previous investigations, and it is concluded that fetal and adult rabbit hemoglobin differ in physiological function as well as molecular structure. Contrary to human fetal and adult hemoglobins, the structural differences appear to be responsible for the distinction in the physiological function.

This research has been made possible through the support and sponsorship of the U.S. Department of Army, through its Far East Research Office (Contract No. DA92-557-FEC-36081) to which authors' thanks are due.

\section{REFERENCES}

1) Von Körber, E.: Inaug. Diss., Dorpat, 1866.

2) Schroeder, W.A., Shelton, J.R., Shelton, J.B. And Cormick, J.: Proc. Natl. Acad. Sci. U.S. $48: 284,1962$.

3) Hasselhorst, G. And Stromberger, K.: Z. Geburtsh. Gynäkol. 98: 49, 1930.

4) Litarczek, C., Sloboziano, H., Aubert, H. and Cosmulesco, I.: Compt. rend. soc. biol. $104: 710,1930$.

5) Eastman, N.J., Gelling, E. M.K. And Delawder, A.M.: Bull. Johns Hopkins Hosp. $53: 246,1933$.

6) Darling, R.C., Smith, C. A., Asmussen, E. And Cohen, F. M.: J. Clin. Invest. 20: 739, 1941.

7) McCarthy, E.F.: J. Physiol. $102: 55,1943$.

8) Barcroft, J.: Researches on Prenatal Life, Blackwell Scientific Publ., Oxford, 1946.

9) Leibson, R.C., Likhnitzky, I. I. And Sax, M.G.: J. Physiol. 87: 97; 1936.

10) Allen, D. W., Wrman, J. Jr. And Smith, C. A.: J. Biol. Chem. 203 : 81, 1953.

11) Jonxis, J.H.P. And Visser, H. K. A.: Amer. J. Dis. Child. 92: 588, 1956.

12) Smithies, O.: Biochem. J. 61: 629, 1955.

13) Poulik, M.D.: Nature 180: 1477, 1957.

14) Gratzer, W.B. And Beaven, G.H.: Clin. Chim. Acta 5: 557, 1960.

15) Enoki, Y., Tomita, S. And Morikawa, S.: Kagaku 33: 316, 1963.

16) Owen, J.A., Silberman, H. J. and Goto, C.: Nature 182: 1373, 1958.

17) Boyer, P.D.: J. Amer. Chem. Soc. 76: 4331, 1954.

18) Enoki, Y.: Nippon Seirigaku Zasshi 21 : 1013, 1959.

19) Van Slyke, D. D. And Plazin, J.: Micromanometric Analyses Williams \& WiLkins, Baltimore, 1961.

20) Enoki, Y.: Nara Igaku Zasshi 10: 345, 1959.

21) Beaven, G.H., Hoch, H. And Holiday, E.R.: Biochem. J. 49: 374, 1951.

22) Huisman, T.H. J. And Prins, H. K.: J. Lab. Clin. Med. 46: 255, 1955.

23) Cabannes, R. And Serain, C.: Compt. rend. soc. biol. 140: 1193, 1955.

24) Giri, K. V. And Pillai, N.C.: Nature 178: 1057, 1956. 
25) Saha, A., Dutta, R. And Ghosh, J.: Science 125: 447, 1957.

26) Haurowitz, F.: Z. physiol. Chem. 232: 125, 1935.

27) Schruefer, J.J.P., Heller, C. J., Battaglia, F.C. And Hellegers, A. E.: Nature 196: 550, 1962.

28) Allen, D.W. And Jandl, J.H.: J. Clin. Invest. 39: 1107, 1960.

29) Barron, D. H. and Meschia, G.: Cold Spring Harbor Symp. Quant. Biol. 19: 93, 1954.

30) Beer, K., Doll, E. And Wenner, J.: Pflügers Arch. ges. Physiol. 265: 526, 1958.

31) Morse, M. And Cassels, D. E.: J. Clin. Invest. 8 : 1091, 1950.

32) Bartels, H., Hilpert, P. and Riegel, K.: Pflügers Arch. ges. Physiol. 271 : 169, 1960.

33) Hal. , F.G.: J. Physiol. $82: 33,1934$.

34) Muller, C. J.: Molecular Evolution, Van Gorcum, Assen, 1961.

35) Riggs, A.: J. Gen. Physiol. 43: 737, 1960.

36) Cecil, R. and Snow, N.S.: cited by Gratzer, W. B. \& Allison, A.C. in Biol. Rev. 35: 459, 1960. 